NBER WORKING PAPER SERIES

EFFICIENT WINDOWS AND LABOR FORCE REDUCTION

Robin L. Lumsdaine

James H. Stock

David A. Wise

Working Paper No. 3369

\author{
NATIONAL BUREAU OF ECONOMIC RESEARCH \\ 1050 Massachuserts Avenue \\ Cambridge, MA 02138 \\ May 1990
}

This paper is part of NBER's research programs in Aging and Labor Studies. Any opinions expressed are those of the authors and not those of the National Bureau of Economic Research. 
NBER Working Paper \#3369

May 1990

\section{EFFICIENT WINDOWS AND LABOR FORCE REDUCTION}

\section{ABSTRACT}

Recently many U.S. firms have offered "window" plans that provide bonuses to a group of workers if the worker retires within a specified short time span. This paper examines a window plan at a Fortune $500 \mathrm{firm}$, and addresses two main issues. First, what was the effect of the window plan on departures? Second, assuming a variety of possible firm objectives, what would be the design of an efficient window plan? These questions are addressed using the retirement model in Stock and Wise $[1988 \mathrm{a}, 1988 \mathrm{~b})$. The model, estimated using data for an earlier year, predicts well out-of-sample the subsequent large increase in retirements under the window plan. We find that while the firm successfully maximized departures, if its goal was to minimize either expected future wage payments or the current cost per induced retirement, the firm could have saved more with efficient plans constructed using the model. One interpretation is that the firm was primarily interested in reducing the overall size of the labor force or in retiring older employees to allow promotion of younger employees.

Robin L. Lumsdaine Department of Economics Littauer Center Harvard University Cambridge, MA 02138
James H. Stock Kennedy School of Government Harvard University 79 Kennedy Street Cambridge, MA 02138
David A. Wise

Kennedy School of Government Harvard University 79 Kennedy Street Cambridge, MA 02138 
In recent years many U.S. firms have offered "window" plans that provide incentives for older workers to retire early. Window plans provide special bonuses to a specific group of workers - - often defined by age, occupational group, or even a division within the firm -. If the worker retires within a specified period of time, typically a year or less. The apparent goal of such plans is either to reduce the salary cost of older employees or to reduce the size of the older labor force, possibly without primary concern for total labor cost. Some firm executives emphasize that by inducing employees in higher level positions to retire such plans can enhance promotion possibilities for younger employees. Others emphasize that such plans are a convenient way to reduce the overall size of the workforce without resorting to layoffs. Another possibility is that firms use the window plan to induce older workers to retire because their salaries would exceed their marginal products, were they to continue working. This is in line with the theoretical proposition of Lazear [1979], that defined benefit pension plans serve this purpose in general. The window plan might be an additional inducement motivated by the same goal. With these possible goals in mind, this paper considers the potential effects of "optimal" window plans. To focus the discussion and to demonstrate the effects of window plans, the analysis is

\footnotetext{
*Financial support was provided by the National Institute on Aging, grant numbers R37 AG08146 and T32 AG00186, the Hoover Institution, and the National Science Foundation.
} 
applied to the experience of a large Fortune $500 \mathrm{firm}$. We consider whether the window plan in this firm was as efficient as it could have been; was there another plan that could have done the job better?

The analysis relfes on the option value model developed in earlier papers [Stock and Wise 1988a and 1988b] and used to analyze the retirement incentives of defined benefit pension plans. About 50 percent of workers in the United States have firm pension plans. Approximately 75 percent of these are covered by defined benefit plans. ${ }^{1}$ The typical defined benefit pension plan provides substantial incentive for workers to retire early, often as young as 55 . Most window plans can be treated as temporary changes in the provisions of firm pension plans.

Firm pension plan coverage expanded quickly in the late 1940's and the 1950's, after 1942 legislation that made contributions to pension funds tax deductible. Although total coverage has not changed much in recent years, the proportion of workers that retires with a firm plan is still increasing. The rapid increase of pension plan coverage has been accompanied by a dramatic decrease in the labor force participation of older workers, as shown by the following data for men:

\section{Male Labor Force Participation Rates, by Age}

$\begin{array}{lrrrl}\text { Year } & \underline{50-54} & \underline{55.59} & \underline{60-64} & \underline{65 t} \\ 1971 & 92.8 & 88.8 & 74.1 & 25.5 \\ 1986 & 88.9 & 79.0 & 54.9 & 17.5\end{array}$

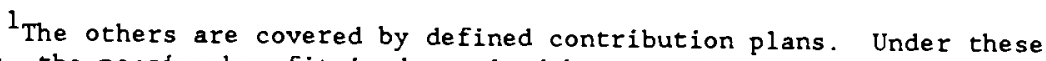
plans, the pension benefit is determined by contributions to the firm pension fund, which are in turn usually set at a percentage of salary earnings. Defined contribution plans typically have none of the incentive effects of defined benefit plans, as described below. 
The juxtaposition of these two trends suggests that the quantitative effects on retirement of firm pension plan provisions may have been substantial.

The incentive effects of these plans have been emphasized in several recent papers. Bulow [1981] described pension wealth accrual under such plans and Lazear [1983] emphasized the potential role of plan provisions in inducing early retirement as a substitute for mandatory retirement. The very substantial incentive effects of these plans have been emphasized most recently by Kotlikoff and Wise $[1985,1987,1989]$, who summarize the incentives of approximately 2500 plans covered by the Bureau of Labor Statistics Level of Benefits Survey and consider in detail the effects of the provisions of the same Fortune 500 firm whose data is used in this paper. This work demonstrates that the typical firm plan provides a large reward for remaining with the firm until some age, often the early retirement age, and then a substantial inducement to leave the firm, often as early as 55 . Almost all plans incorporate a large penalty for working past age 65 . The gain in wage earnings from working an additional year is of ten offset in large part by a loss in the present value of future pension benefits.

An early analysis of firm retirement is presented in Burkhauser [1979]. Fields and Mitchell [1982] also consider the incentive effects of firm plans. Hogarth [1988] analyzes the acceptance of an early retirement bonus. The immediate antecedent of our work is Lazear and Moore [1988], who argue that the option value of postponing retirement is the appropriate variable to enter in a regression equation explaining retirement. ${ }^{2}$ The analysis by Stock and

2 Indeed it was their work and analysis of military retirement rates by Phillips and Wise [1987] that motivated the Stock and Wise option value approach. 
Wise [1988a and 1988b] formalizes an option value model of retirement and demonstrates that these plans do indeed have a powerful effect on employee retirement decisions. Based on data from the Fortune $500 \mathrm{firm}$ used in this paper, they showed that increasing the age of early retirement from 55 to 60 , for example, would increase by 35 percent the proportion of persons employed at 50 who are still employed by the firm at age 60 . They also showed that changes in Social Security provisions would have little effect on retirement rates in this firm, largely because most firm employees have retired before the Social Security early and normal retirement ages, 62 and 65 respectively.

This paper uses the option value model to examine the potential effect of window plans. To understand the effect of these plans, it is first necessary to understand the retirement incentive implications of the firm's permanent pension plan. A brief description of the firm plan, borrowed in large part from Stock and Wise [1988a], is presented in section I. The model that is used to analyze retirement is summarized in section II. To support the subsequent selection of optimal window plans, two results are emphasized: first, the firm's window plan dramatically increased firm departure rates, and, second, the option value retirement model predicts well these very large increases in retirement rates. In addition to the choice of an optimal window plan, the central focus of this paper, the firm window allows a unique external test of the predictive validity of the retirement model; we compare our predictions against actual retirement rates under the window plan. ${ }^{3}$ The model is first estimated for male non-managerial office employees, using data for 1980, a year in which no window plan was avallable. The model is then

${ }^{3}$ More detail on this aspect of the analysis, which is only summarized in this paper, is presented in Lumsdaine, Stock, and Wise [1989]. 
used to predict the effect of the window plan that was offered two years later, in 1982. This firm had not offered previous window plans and according to firm executives the 1982 plan was unanticipated by employees. Thus prediction of departure rates under the plan provides a true out-of-sample test of the predictive validity of the model. ${ }^{4}$ The results show that the model predicts well the effects of the window plan adopted by the firm. We then consider in section III how an "optimal" plan could be designed, and what the effects of such a plan would be.

Although to motivate the analysis we consider how well the firm's plan worked relative to potential alternative plans with similar characteristics, the primary intent is to demonstrate that window plans can be a powerful managerial tool with strong incentive effects, and to demonstrate how such plans could be designed. The provisions of optimal plans are chosen in accordance with the parameter estimates of the retirement model.

The firm's plan was apparently chosen on the basis of educated hunches of firm personnel. In contrast, we choose an "optimal" plan based on our estimated model of retirement behavior, together with an objective function. We find that an optimal plan chosen to minimize expected future salaries paid to older employees could have saved much more than the firm's plan, measured by reduction in salaries per bonus dollar. Thus if this were its goal, the firm could have chosen a more efficient mechanism to achieve it. We also show that an optimal plan could reduce substantially the current cost of the window plan per induced retirement. Although the results provide no direct evidence on the motivation of the firm in inftiating a window plan, the analysis

\footnotetext{
${ }^{4}$ The estimates in the earlier Stock-Wise papers were based on salesmen, who were not eligible for the window plan.
} 
supports some qualified conclusions about possible motivations for such plans. Section IV is a summary.

I. The Firm Pension Plan and The Temporary Window.

A. The Firm Pension Plan.

The analysis is based on male (non-managerial) office employees who are at least 50 years old and have been employed for at least three years. 5 The data reflect the retirement behavior of a random sample of 1000 employees who were in the firm on January 1, 1980. The data, obtained trom firm personnel records, follow these employees through 1985. Individual earnings historles are available beginning in 1969 , or from the date of hire if the employee was hired after 1969.

To understand the effect of the pension plan provisions, figure 1 shows the expected future compensation of a person from our sample who is 50 years old and has been employed by the firm for 20 years. 6 It is important to consider total compensation - Including wage earnings, the accrual of pension benefits, and the accrual of Social Security benefits. As compensation for working another year the employee recelves salary earnings. He also receives compensation in the form of future pension benefits. The annual compensation in this form is the change in the present value of the future pension benefits entitlement, due to working an additional year. This accrual is comparable to

5 The criterion that they be employed three years facilitates the forecasting of future wage earnings on an individual basis.

${ }^{6}$ The graphs assume a 5 percent real discount rate and zero inflation. In the empirical model that is estimated, the discount rate is estimated and the inflation rate is assumed to be 5 percent. 
wage earnings. The accrual of Social Security benefits also may be calculated in a similar manner, and is also comparable to wage earnings. Figure 1 shows the present value at age 50 of expected future compensation in all three forms. The line labelled wage earnings represents cumulated earnings, by age of retirement. ${ }^{7}$ For example, if the person were to retire at age 62 , his cumulated earnings between age 50 and age 62, discounted to age 50 dollars would be about $\$ 126,000$. (A11 dollar amounts are in 1980 dollars.) The slope of the earnings line represents annual earnings discounted to age 50 dollars.

The solid line shows the accrual of firm pension plus Social Security benefits, again discounted to age 50 dollars. The shape of this profile is determined primarily by the pension plan provisions. The plan's normal retirement age is 65 and the early retirement age is 55 . Cliff vesting occurs at ten years of service. 8 Normal retirement benefits at age 65 are determined by age times years of service, times a multiplier. The most important additional provisions - those that determine the shape of the profile in figure 1 -. are described here. ${ }^{9}$ The present value of retirement benefits increases between 50 and 54 because years of service, and possibly earnings, increase. If a vested employee were to leave the firm at age 53, for example, he would be entitled to normal retirement pension benefits at age 65 , based on his years of service and current dollar earnings at age 53 . He could start to

7 Departure from the firm would be a more accurate description than retirement, because for some employees the alternative to continued employment at the firm may to be another job, rather than retirement.

${ }^{8}$ That is, an employee has no pension entitlement before 10 years of service, when he becomes entitled to full benefits determined by the pension formula.

${ }^{9}$ Full details of the plan provisions are presented in Kotlikoff and Wise [1987]. 
recelve benefit payments as early as age 55, the pension early retirement age, but the benefit amount would be reduced actuarially. Thus in present value terms, the stream of benefits received beginning at 55 would be equal to the stream of benefits beginning at 65 ; the annual benefit amount would be reduced just enough to offset the receipt of benefits for ten more years. If he started to receive benefits at age 55 , they would be only 36 percent of the dollar amount he would receive at age 65 . If, however, he were to remain in the firm until the early retirement age, the situation would be quite different. He would be entitled to normal retirement benefits based on his years of service and salary at age 55 . But if he were to start to receive them at age 55 the benefits would be reduced less than actuarially, about 3 percent for each year that retirement precedes age 65 instead of the actuarial rate of 6 or 7 percent.

The plan also has a Social Security offset provision. Pension benefits are offset by a specified amount, depending on the firm estimate of Social Security benefits. But if the person takes early retirement, between 55 and 65 , the Social Security offset is not applied to benefits received before age 65. These two provisions create the large discontinuous jump in retirement benefits at age 55 - from about $\$ 30,000$ to $\$ 50,000$. This increase is equivalent to more than 150 percent of his annual wage earnings at 55 . Thus there is an enormous bonus for remaining with the firm until that age. After age 55, however, the person who does not retire foregoes the opportunity of taking pension benefits on very advantageous terms; thus there is only a small change in the discounted value of benefits between 55 and 60 .

If a person has 30 years of service at age 60 , he is entitled to full normal retirement benefits. No early retirement reduction is applied to 
benefits if they are taken then. That is, by continuing to work after age 60 he will no longer gain from fewer years of early retirement reduction, as he did before age 60 . Thus the kink in the profile and the decline thereafter.

The top line shows total compensation. For example, if the employee were to leave the firm at age 60 , his wage earnings between 50 and 60 would be $\$ 114,000$, shown by the wage earnings line. Thereafter, he would receive firm pension plan and Social Security retirement benefits with a present value -. at age 50 - of about $\$ 45,000$. The sum of the two is about $\$ 159,000$, shown by the top line. The large jump at 55 reflects the early retirement provisions of the pension plan. Total annual compensation declines modestly each year through age 60 and very rapidly thereafter. After age 62 or 63 , total annual compensation is close to zero. The plot ends at age 70 , which was the mandatory retirement age in this firm over the period of our analysis.

\section{B. The Window Plan}

In 1982 the firm introduced a window plan for all non-managerial office employees. The window plan applied to all employees 55 and older who were vested in the firm's pension plan. Employees in this age group who retired in 1982 received a bonus, depending on age and years of service. The approximate number of bonus months is shown in table 1.10 The bonus was typically smallest for the youngest and for the oldest employees and largest for those who were between 58 and 62 years old.

${ }^{10}$ The approximation is obtained from the parameterization of bonus plans used to choose optimal windows. It is discussed below. To avoid potential identification of the $\mathrm{firm}$, we do not show the actual plan values. 
II. The Option Value Kodel, Parameter Estimates, and Predictive Validity.

A. The Model.

The conceptual model is discussed in detail in Stock and Wise [1988a]. It is described only briefly here. At any given age, based on information available at that age, we assume that an employee compares the expected value of retiring at that age with the value of retiring at each age in the future, through age 70 . The difference between the value of immediate retirement versus the maximum of the values at each future age represents an opportunity cost of retirement; we refer to it as the option value of postponing retirement. A person who does not retire this year maintains the option of retiring at a more advantageous age later on. If the option value is greater than zero, the person continues to work; otherwise he retires. With reference to figure 1, for example, at age 50 the employee would compare the value of the retirement benefits that he would receive were he to retire then .. approximately $\$ 24,000$.. with the value of wage earnings and retirement benefits in each future year. The expected value at 60 , for example, is about $\$ 159,000$. The same calculation is repeated in successive years, using updated predictions of future wage earnings, and related pension and social security benefits. Future earnings forecasts are based on the individual's past earnings, as well as the earnings of other persons in the firm. The precise model specification follows.

A person at age $t$ who continues to work will earn $Y_{s}$ in subsequent years $s$. If the person retires at age $r$, subsequent retirement benefits will be $B_{s}(r) .11$ We suppose that in deciding whether to retire the person weighs the

11 These benefits will depend on the person's age and years of service at retirement and on his earnings history; thus they are a function of the retirement age. 
Indirect utility that will be recelved from future income. Discounted at the rate $\beta$, the value of this future stream of income if retirement is at age $r$ is given by

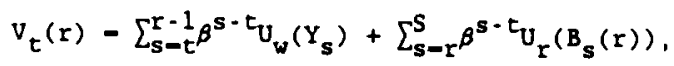

where $U_{w}\left(Y_{s}\right)$ is the indirect utility of future wage income and $U_{r}\left(B_{s}(r)\right.$ ) is the indirect utility of future retirement benefits. The person will not live past age $S$.

The person will postpone retirement at age $t$ if the option value - the gain from postponing retirement - is greater than zero, that is if

$$
G_{t}\left(r^{*}\right)-E_{t} v_{t}\left(r^{*}\right)-E_{t} v_{t}(t)>0
$$

where $r^{\star}$ is the age that gives the maximum gain.

The utilities of future wage and retirement income are assumed to be given by

$$
\begin{aligned}
& U_{w}\left(Y_{s}\right)-Y_{s}^{Y}+w_{s} \\
& U_{r}\left(B_{s}\right)=\left(k B_{s}(r)\right)^{Y}+\xi_{s}
\end{aligned}
$$

where $\omega_{s}$ and $\xi_{s}$ are individual-specific random effects, assumed to follow a first order autoregressive process

(4a)

$$
w_{s}=\rho w_{s-1}+\epsilon_{w s}, E_{s-1}\left(\epsilon_{w s}\right)=0
$$


(4b)

$$
\xi_{s}-\rho \xi_{s-1}+\epsilon_{\xi s} \cdot E_{s-1}\left(\epsilon_{\xi s}\right)-0 .
$$

The parameter $k$ is to recognize that in considering whether to retire the utility associated with a dollar of income while retired may be different from the utility associated with a dollar of income accompanied by work.

Given this specification, the function $G_{t}(r)$ can be decomposed into two components

$$
G_{t}(r)=B_{t}(r)+\phi_{t}(r)
$$

where $g_{t}(r)$ and $\phi_{t}(r)$ distinguish the terms in $G_{t}(r)$ containing the random effects, $w$ and $\xi$, from the other terms. They are given by

$$
\begin{aligned}
g_{t}(r)= & \sum_{s-t}^{r-1} \beta^{s-t} \pi(s \mid t) E_{t}\left(Y_{s}^{\gamma}\right) \\
& +\sum_{s-r}^{S} \beta^{s-t} \pi(s \mid t)\left[E_{t}\left(k B_{s}(r)\right)^{\gamma}\right] \\
& -\sum_{s-t}^{S} \beta^{s-t} \pi(s \mid t)\left[E_{t}\left(k B_{s}(t)\right)^{\gamma}\right]
\end{aligned}
$$

$$
\phi_{t}(r)=\sum_{s=t}^{r-1} \beta^{s-t} \pi(s \mid t) E_{t}\left(\omega_{s}-\xi_{s}\right)
$$

where $\pi(s \mid t)$ denotes the probability that the person will be alive in year $s$, given that he is alive in year $t$. Given the random Markov assumption, $\phi_{t}(r)$ can be written as

$$
\begin{aligned}
\phi_{t}(r) & =\sum_{s=t}^{r-1} \beta^{s-t} \pi(s \mid t) \rho s-t\left(\omega_{t}-\xi_{t}\right) \\
& =k_{t}(r) \nu_{t} .
\end{aligned}
$$


where $K_{t}(r)=\sum_{s-t}^{r-1}(\beta p)^{s-t} \pi(s \mid t)$ and $\nu_{t}=w_{t}-\xi_{t}$. Thus $G_{t}(r)$ can by written as

$$
G_{t}(r)-g_{t}(r)+K_{t}(r) v_{t}
$$

If the person is to retire in year $t, G_{t}(r)$ must be less than zero for every potential retirement age $r$ in the future. If $r^{\dagger}$ is the $r$ that yields the maximum value of $g_{t}(r) / K_{t}(r)$, the probability of retirement becomes

$$
\operatorname{Pr}[\text { Retire in year } t]-\operatorname{Pr}\left[g_{t}\left(r^{\dagger}\right) / K_{t}\left(r^{\dagger}\right)<-\nu_{t}\right] .
$$

Consistent with equation (4), $\nu_{s}$ follows a first order autoregressive process that we assume to be Gaussian. Thus

$$
\nu_{s}=\rho \nu_{s-1}+\epsilon_{s}, \quad \epsilon_{s} \text { 1.1.d. } N\left(0, \sigma_{\epsilon}^{2}\right) \text {. }
$$

The estimates in this paper are based on retirement decisions in only one year (1980) and the random terms in equation (4) are assumed to follow a random walk, with $\rho=1.12$

B. Parameter Estimates.

The maximum likelihood parameter estimates and standard errors are:

12 Estimates for salesmen based on several consecutive years and with $\rho$ estimated are reported in Stock and Wise [1988a]. These generalizations have ittle effect on the estimates. 


$\begin{array}{cccc}\boldsymbol{x} & \underline{\mathbf{k}} & \underline{\boldsymbol{r}} & \underline{\boldsymbol{\sigma}} \\ 0.523 & 1.483 & 0.014 & 0.156 \\ (0.066) & (0.303) & (0.011) & (0.023)\end{array}$

The risk aversion parameter $\gamma$ is .523 . Interpreted literally, this means that the certainty equivalent of $\$ 10,000$ with probability .5 and $\$ 20,000$ with probability .5 is $\$ 14,591$, suggesting that these employees are essentially risk neutral. ${ }^{13}$ The estimated value of $k, 1.483$, indicates that, in deciding whether to retire, a dollar of income while retired is given more weight than a dollar of income while working. The ratio of the utility of retirement to the utility of employment is $[1.483(B / Y)]^{.523}$. It is 1 when $B / Y=0.67$. The real discount rate is estimated at .014 . This is an unusually low estimate, based on our experience to date with this model. 14

Alternative specifications were also estimated but are not reported here. One parameterized $k$ as a function of age. Although this specification fits the data better than the specification reported above, simulations like those reported below are not appreciably affected. 15

\section{The Model Fit.}

To evaluate the model fit, the predicted versus actual retirement rates are shown in figure 2. The first panel of the figure shows the proportion of persons employed at age 50 who still would be in the firm at subsequent ages,

${ }^{13}$ Logarithmic utility is clearly rejected by the data, based on the wald statistic.

${ }^{14}$ Estimated discount rates for salesmen have typically been above .15 . Thus we do not at this stage of our work attach much significance to the exact rate estimated here.

15 For more detall on these other specifications see Lumsdaine, Stock, and Wise [1989]. 
based on the annual retirement (hazard) rates that are shown in the bottom panel of the figure. 16 In general the model fits the data rather well. There are two exceptions: It overpredicts the hazard rates between 56 and 59; thus the cumulative rates in subsequent years, as shown in the top panel, are somewhat overpredicted between 55 and 65 . And, the retirement rate at 65 , is substantially underpredicted. Although the small sample size at age 65 does not support strong conclusions based on these estimates alone, our experience with other employee groups suggests that the model typically underpredicts age 65 retirement rates. As can be seen in figure 1, wage earnings and retirement income do not suggest an abrupt jump in retirement at $65 \cdots$ as compared to the jump that the figure suggests at 55 . Most employees in this firm have retired before 65 , so the effect on overall retirement of the hazard rate at 65 is small. Nonetheless, these results and the results of our prior estimation all point to a "customary retirement effect" or a "Social Security retirement effect" at age 65, and possibly at age 62 as well, that is not due to an abrupt change in wage earnings or retirement income at that particular age. 17

16 The "actual" values in the bottom panel in figure 2 were computed as the fraction of workers in each age group who retired in 1980 . The "predicted" values were computed from the estimated model. The cumulative hazard in the top part of figure 2 was computed by cumulating the annual hazards in the bottom panel using the formula $h_{1}-1 \cdot \prod_{j-1}^{1}\left(1-f_{j}\right)$ where $f_{j}$ is the annual hazard in the bottom half of the figure for age $j$ and 1 runs over ages. The annual and cumulative hazards presented in figures 3 through 9 were computed analogously. The data that correspond to figures 2,3 , and 4 are shown in Lumsdaine, Stock, and Wise [1989].

17 The "actual" rates - the sample rates .. are of course only estimates themselves. Except at age 65 , the predicted rates always 11 e within a 95 percent confidence band (for the true rates) around the "actual" sample rates. Lumsdaine, Stock, and Wise [1989] show that the fit is somewhat better when $k$ is parameterized as a function of age. The utility function $\left(k B_{s}(r)\right)^{\gamma}$ can be interpreted as the utility associated with a dollar of income while retired. Maintaining this interpretation, its value might be expected to rise with age, not because the dollar itself is worth more but because retirement is.

Holding income constant, retirement (leisure) may be increasingly desired as the person ages. To capture this possibility, $k$ was parametrized as $k-k_{0} /[1$ $\left.+\exp \left(-k_{1}\left(A-k_{2}\right)\right)\right]$. Recalling the ratio of the utilities of retirement to 


\section{Predictive validity.}

The simulated effect of the 1982 window plan is shown in figure 3 . The base case represents the simulated rates under the usual plan provisions. The simulated retirement rates under the window plan exceed those in the absence of the plan by almost two fold in some instances. For example the simulated hazard rate at age 60 is .193 without the window plan and .364 with 1 t. of persons employed at age 52, about 52 percent retire by age 60 under the normal plan; with the window plan in effect, almost 79 percent are estimated to retire by age 60 , an increase of over 50 percent. 18

In order of magnitude, the effect of the window plan is comparable to the effect of changing the plan early retirement age, a key feature of the pension plan. Whereas almost 49 percent of persons employed at 50 leave the firm before age 60 with the early retirement age at 55 (based on the estimates for 1980), only about 35 percent would leave before 60 if the early retirement age were at age 60 , a reduction of about 28 percent. Similarly, were the early retirement age at 60 , a reduction to 55 would increase by about 39 percent the proportion that would leave before age 60.19 Thus the window plan magnifies the already large effect of the pension plan early retirement provisions.

employment, $\left[k\left(B_{s} / Y_{s}\right)\right]^{\gamma}$, if $k$ is very small retirement will be unlikely even if $B / Y$ is large; if $k$ is large retirement is likely even if $B / Y$ is small. The results suggest an increasing desire for retirement leisure with age.

18 Because the youngest person in the 1982 sample is 52 , the cumulative calculations start at that age. In figure 3 we have adjusted the 1982 data by using the age 50 and age 51 retirement rates from 1980 and 1981 .

${ }^{19}$ The details of these calculations are reported in Lumsdaine, Stock, and Wise [1989]. 
A natural way to assess the predictive validity of the model is to consider the extent to which the predicted (i.e. simulated) retirement rates agree with the actual rates under the window plan. The evidence is shown in figure 4. As a reminder of the extent to which the window plan changed the typical retirement behavior, the actual 1981 retirement rates are also shown. The top panel of the figure summarizes the results. It is evident from a comparison of the 1981 and 1982 rates that the effect of the window plan on retirement was substantial. The window plan was not announced prior to its effective date. Thus there should have been no anticipation of it, leading to reduced retirement in 1981 while waiting for the more favorable 1982 terms. 20 Thus a good external test of the predictive validity of the model is its ability to predict actual retirement rates in 1982, rates that were much different than they would have been without the window plan. In general the correspondence between the actual and predicted rates is rather close. The simulated proportion of those employed at age 50 who would retire by age 60 under the window plan almost matches the actual proportion, .795 versus .770 respectively. The simulated results, however, overpredict annual retirement rates from 55 to 58 and underpredict for older ages. This can be seen clearly in the annual hazard rates reported in the bottom panel of the figure.

The parameter estimates for men were also used to predict the effect of the window plan on women. Although not shown here, the prediction for women, based on the parameter estimates for men, seems to match the actual retirement experience of women better than the predictions for men match their actual

${ }^{20}$ The 1981 retirement rates are essentially the same as those in 1980 and these are in turn virtually the same as those in 1983, the year after the window plan. 
experfence. In summary, the model clearly captures the pattern and magnitude of the effects of the window plan, but underpredicts somewhat the effect on the small proportion of employees that would otherwise remain in the firm at older ages.

III. "OpeImal" Window Plan.

It is clear from the discussion above that the window plan in this firm had a dramatic effect on retirement rates during the year that it was in effect. Thus it 1s apparent that such bonus plans can be an Important manpower management tool. We consider next the possibility of choosing an efficlent plan, based on managerlal goals. To make the 1dea concrete, we consider in particular whether in this firm the same outcomes could have been achieved at less cost with an alternative window plan. To 1llustrate the possible effects of larger bonuses and to motivate the possible advantages of targeting certain groups of employees, we first simulate the effects of two simple plans that provide the same bonus for all older employees.

\section{A. Six versus Twelve Month Bonuses for Everyone.}

The firm plan offered bonuses ranging from 3 to 12 months salary to vested employees between 55 and 69 . Suppose instead that each employee between 55 and 69 were eliglble for a bonus of six months salary if he were to retire in 1982. The simulated effect of such a plan is shown in figure 5 , together with the simulated retirement rates with no window plan and with the firm's plan. The figure also shows the simulated effect of offering each employee a 12 month salary bonus. The effect of both the 6 and the 12 month bonus plans is large, but the flgure makes it clear that the increase in retirement rates from the addition of the second 6 months is much less than 
the increase from the first 6 months. A total of 55.7 retirements are induced by the six-month and 80.8 by the twelve-month plan, according to the simulations. (Without the window plan, 91.0 employees would retire; 146.7 are estimated to retire under the 6 -month and 171.8 under the 12 -month bonus.) In both cases the relative increase in retirement rates is greater for younger than older employees. Thus, the illustration suggests that if the goal were to reduce the number of older employees, it would be best to target younger rather than older workers in the 55 to 65 age group. Those closer to 65 have high retirement rates with no bonus at all, and thus the marginal effect of the bonus is smaller.

\section{B. Parameterizing the Window Plan.}

Like most window plans, the plan at this firm provided bonuses to a rather broad group of employees. The amount of the bonus payment was determined by age and years of service. A natural question is whether another plan, offering a different schedule of payments, wight be more efficient than the firm's plan. For example, could another plan achieve the same results at lower cost? In general, to find such a plan requires that a bonus be selected for each age and years of service combination. While conceptually straightforward, this direct approach is computationally cumbersome; optimization is over a large number of parameters, given by the number of ages times the possible number of years of service. We therefore adopt an alternative approach based on parameterization of the schedule of bonus payments by age and years of service. We use a varlant of the beta distribution to provide a flexible functional form that can describe a wide range of possibilities. Months of bonus payment are given by 


$$
\text { Months }-f \star \frac{\Gamma(\mu+\nu)}{\Gamma(\mu) \Gamma(\nu)}\left[(1-x)(\mu-1) x^{(\nu-1)}\right]
$$

where $\mathrm{x}$ - (age - 55)/15. The standard beta distribution is defined for variable values between 0 and 1 . The transformation of $x$ allows age to range from $55(x-0)$ to $70(x-1)$. The maximum of 70 is chosen because the firm's mandatory retirement age was 70 . The central tendency of the density along the age dimension is allowed to vary with years of service, by letting $\nu-\nu_{1}-\nu_{2}$ (years of service - 55). The parameter $f$ is a normalizing factor that determines the overall level of payments. Alternative plans are defined by different parameter values in equation (11).

Because we use the "beta description" of the firm's plan as a base case, we need to verify that the beta formulation can accurately approximate that plan. The beta description of the firm's plan was obtained by fitting the specification in equation (11) to the actual window plan payment schedule, using least squares. Even though the firm's schedule varies discontinuously by age and years of service, the approximation fits the actual schedule rather closely. The root mean squared error of the predicted versus actual bonus for employees with 10 to 40 years of service is 1.17 months of salary, less than 10 percent of the typical bonus. More important for our purposes, the predicted departure rates using the actual firm bonus payments correspond closely to the predicted rates using the beta summary of the firm's plan. The cumulative and the annual hazard rates based on the actual and fitted payments are shown in figure 6 .

\section{c. Selecting Optimum Plans.}

Whether a window plan is efficient depends, of course, on the goal of the plan. In line with prominent explanations for such plans, we consider two 
goals: one is to reduce the wage bill, through retirement of older workers; the other is to reduce the number of older employees, without particular concern for labor cost.

\section{Reducing Labor Cost.}

Suppose that the firm wishes to reduce labor cost. We translate labor cost to mean the present discounted value of the expected future wage bill. We then select a window plan to minimize the future wages that the firm would otherwise expect to pay to the firm's current older employees before they retire, plus the cost of the window plan bonus payments. Here, we consider only male non-managerial office employees. The criterion function is

$$
\sum_{1-1}^{N}\left[\sum_{t-a_{1}+1}^{70}(1 / 1+r)^{t-a_{1}} H_{1}\left(t \mid a_{1}, x_{1}\right) Y_{1}\left(t \mid s_{1}, a_{1}\right)+c_{1}\right] \text {, where }
$$

$$
C_{1}-\left[1-H\left(a_{1}+1 \mid a_{1}, x_{1}\right)\right]\left[M\left(a_{1}, s_{1}\right)\right]\left[Y_{1}\left(a_{1}\right) / 12\right]
$$

Here, $N$ is the number of employees (taken to be the 563 employees in our sample who were employed on January 1, 1982), I indexes employees, a is age, I is the discount rate (assumed to be 5 percent), $\mathrm{H}\left(\left.\mathrm{t}\right|^{\circ}\right.$ ) is the probability that a person will still be employed at future ages $t, x$ includes all of the measured determinants of retirement including the window bonus. $Y$ is predicted future annual salary, and $C$ is the expected window plan bonus paywent. The number of months of salary under the window plan is M. 21 Minimization of equation (12) is with respect to the beta function parameters in equation (11), which in turn determine the bonus months $M$.

21 The forecasting of future salary is based on individual age, years of service, and current salary, as well as the salaries of other firm employees.
The procedure is described in stock and Wise [1988b]. 
The optimal plan bonus schedule is shown in table 2. For comparison, the table also shows the beta approximation to the firm's plan. There are three noticeable differences between the two. First, the optimal plan offers much lower bonuses on average. This is consistent with the declining marginal effect of additional bonus dollars on departure rates, illustrated in figure 5. Second, the optimal plan offers the highest payments to younger employees. Because younger employees could work for many more years, inducing them to leave has the greatest effect on the expected future wage bill. Third, years of service is not an important determinant of the bonus in the optimal plan:

The actual firm plan costs $\$ 4.07$ million and saves $\$ 6.42$ million in expected labor costs. Thus the reduction in future salary payment to the older employees is offset in large part by the cost of the window plan itself; the reduction in net labor cost is only $\$ 2.35$ million. Were the firm's goal to reduce labor cost, the simulations suggest that it could do much better than this. The cost of the optimal window plan is only $\$ 2.91$ million, yet it saves $\$ 6.08$ million in expected salaries (95 percent of the salary reduction achieved by the firm plan). The net labor cost reduction achieved by the optimal plan is $\$ 3.17$ million, almost 35 percent more than the reduction achieved by firm plan. Even though the cost of the optimal window plan is only 71 percent of the cost of the firm plan, it induces almost 95 percent as many retirements. 22

${ }^{22}$ The optimal plans were determined using a modified simulated annealing algorithm. This random search algorithm was adopted to avoid potential local optima in choosing the plan parameters. For the cost minimizing plan, the minimization of equation (12) was done without any constraints. To determine the plan that induces the maximum number of retirements, and the plan that maximizes the reduction in future employee years, it was necessary to impose the inequality constraint that the total predicted cost of the optimal plan be no greater than the predicted cost of the actual firm plan. This was achieved by penalizing the objective function if the cost of the optimal plan exceeded the firm plan cost. 
The departure rates induced by the optimal cost minimizing plan versus the firm plan are shown in figure 7. Consistent with larger bonuses for the older employees, the firm plan has a greater effect than the optimal plan on the retirement rates of employees 58 and older.

2. Inducing Retirements.

The goal of the firm may be to reduce the number of older employees, without major concern for the salaries that they would receive. It is clear from the results above that the cost minimizing plan costs much less in bonus payments per induced retirement than the firm's plan $. \$ 19,152$ versus $\$ 25,046$. This is due to the rapidly diminishing returns to marginal bonus dollars with respect to induced retirement, as is made clear by the cost of the six-versus twelve-month plans, shown at the bottom of table 3 .

In addition to the cost-minimizing plan, we selected a plan to maximize the number of induced retirements, setting the plan cost equal to the cost of the firm window plan (i.e. $\$ 4.07$ million). As table 3 shows, the maximum employment reduction is 163.7 , only about 1 percent greater than the number of retirements induced by the firm plan. This indicates that no reallocation of the dollars that the firm spent could significantly increase the number of retirements, although the cost per induced retirement could be much lower.

\section{Reducing Future Years of Employment.}

An alternative to inducing retirements is to reduce the number of future years of employment by older workers. In effect, this weights each induced retirement by the number of future years the person would have been expected to work in the absence of the window plan. The plan that yields the maximum reduction in future years of employment, setting the cost at the cost of the firm window plan, reduces expected future employee years by 264.1 (from 1768.7 
to 1504.6). This is about 12 percent more than the reduction achleved by the firm plan. Thus even though it is not possible to induce more retirements than were induced by the firm plan - given the same plan cost - an optimally chosen plan could reduce future employee years somewhat more than the firm plan did.

IV. Summary and Discussion.

Early retirement window plans have become commonplace in the United States in recent years. Based on the option value model of retirement developed in earlier papers, this paper emphasizes the selection of the most efficient plan. Three objectives are considered: minimizing expected labor cost, maximizing induced retirement, and minimizing expected man-years of work by older employees. The analysis is based on data from a large Fortune 500 firm. In emphasizing the potential to select plans to achieve a given goal, the paper compares the effects of "optimal" plans with the effects of the firm plan.

The paper first highlights the power of window plans to induce early retirement. The firm's plan -. providing bonus payments of 3 to 12 months salary - Increased retirement rates by up to two fold. Such a plan would Increase by 50 percent the proportion of workers employed at 52 that has retired by age 60 . These large increases in retirement rates are predicted rather well by the option value model, suggesting that the model also could serve as a basis for finding optimal window plans. This firm's window plan was unanticipated and was not followed by other such plans. The effect of an anticipated or recurring series of window plans may differ from the effect of 
the firm's plan. The optimal design of sequences of plans is left for future analysis.

As discussed in the introduction, there are several possible reasons for window plans. One is that older workers are paid more than their marginal products - and by implication that the wages of older workers cannot be reduced sufficiently to equate them to their marginal revenue products.- and thus the window, like defined benefit pension plans more generally, is used to induce older workers to retire. This explanation is in line with the most prevalent theoretical explanation for the structure of defined benefit pension plans. 23 A second reason is that the retirement of the older employees makes room for the advancement of younger employees, thereby providing an incentive to younger workers to remain with the firm. Part the opportunity cost of retaining older employees is slower advancement for younger workers. A third reason is simply that the window plan provides a convenient way to reduce the size of the firm's workforce, without having to resort to layoffs. The latter two explanations are often cited by firm executives as the motivation for window plans.

Although our results do not provide direct evidence on the actual motivation for the firm's plan, three sets of findings provide some insight into the likelihood of alternative goals, and, by implication, the goals of other firms that have adopted similar plans.

First, given the cost of the firm's plan, we were unable to find a plan that would induce more older employees to retire, if this were the goal of the plan. Thus if the firm's goal were to induce as many retirements as possible,

${ }^{23}$ See Lazear [1979]. 
the window plan that it selected achieved about as much as was possible, given the plan cost. In contrast, if the goal were to minimize the expected present value of the wage bill of older workers (or to maximize the reduction in future older-employee-years) optimal plans could be found that were much better than the firm's plan. According to our results, the bonuses offered under the firm's plan are too large to be consistent with minimizing the expected future wage bill. The plan chosen to minimize expected labor cost would induce almost 95 percent as many retirements as were induced by the firm's plan, but at only 71 percent of the cost of the firm's plan. This is possible because of the declining marginal effect of bonus payments on induced retirement. For example, over 85 percent of the retirement effect of a 12 month bonus to each employee 55 and older could be achieved with a 6 -month bonus to each employee. The current cost of the firm's plan (just over $\$ 4$ million) is 63 percent of the expected future reduction in labor costs; the ratio is 48 percent under the cost minimizing plan.

Second, the results can be used to calculate implied bounds on the expected future marginal products of the older workers who are induced to retire. Suppose that the firm's goal were to maximize the reduction in the future wage bill less the revenue product of the retiring workers. Including the cost of the window plan 1tself, the net reduction in future labor costs due to the firm's plan is 4.9 percent (from $\$ 47.64$ to $\$ 45.29$ m11lion). But the plan reduces expected discounted years of future employment of older workers by 13.6 percent. ${ }^{24}$ Consider two extreme cases: first, assume that

${ }^{24}$ To obtain this figure, future years of employment are discounted at the same rate ( 5 percent) used to discount real salaries. This was computed using (12) by setting $Y_{j}$ to 1.0 for each worker and by dropping the term in $C_{i}$. The resulting expected discounted future employee-years are: no window plan, 1520.5; firm plan, 1314.5; optimal cost-minizing plan, 1325.9. 
the marginal product of older workers who leave is the same as those who stay. Under this assumption, the 13.6 percent reduction in employment of older workers represents a 13.6 percent reduction in the expected present value of the revenue product of older workers. In this case, then, the plan results in a net loss of 8.7 percent. At the other extreme, assume that the marginal revenue product of the workers who leave is zero.. either their physical product could be zero, or there could be inadequate demand for the output of the firm. In this case, the plan represents a net savings of 4.9 percent. The "break-even" value of the marginal revenue product of the departing workers - such that the reduction in labor cost is equal to the reduction in the value of production -. can be determined by equating the reduction in expected future labor cost to the reduction in expected future revenues: $.049 w-.133 e r$, where $w$ is labor cost, $e$ is employment and $r$ is average marginal revenue product per employee. Thus for the firm to break even Implies that w/er $-.133 / .049-2.71$. That is, on average the retiring employees would have to have been paid over 2.7 times their marginal revenue for the firm's window plan to have a zero effect on net profit.

Third, even the cost-minimizing optimal window is 111 designed if the goal is to increase firm profitability by retiring older employees whose salaries exceed their marginal products. For the cost-minimizing plan to achieve this goal, salaries of older workers would have to exceed their marginal products by at least a factor of over 1.9, assuming that the plan does not target specific employees with low productivity relative to their wages. Under the cost-minimizing plan, labor cost is reduced by 6.7 percent and years of older worker employment by 12.8 percent.

Although we can only speculate about the firm's motivations, we consider these three observations to weigh against the likelihood that the window plan 
was primarily aimed at retiring older workers because they are pald more than their marginal products. Were this the firm's objective, the simulations suggest it could have done better with a much less costly plan. And the implied magnitude of the rents being earned by older workers (wages 2.7 times marginal revenue product) strikes us as implausible. Moreover, were the plan to target the least productive workers, the firm would save at most 4.9 percent of the expected wage bill of older workers, assuming the marginal product of the employees who are induced to retire would otherwise be zero. It is clear, however, that the plan does not explicitly target individual employees: the bonus schedule depends only on age and years of service. Without targeting Individuals, there seems no reason to belleve that the employees with the highest salary to productivity ratios would be the most likely to leave. Rather, these employees are likely to have a more advantageous position with this firm than they could obtaln with another firm, and thus would be the least 1ikely to leave. To the extent that employees leave this firm to take another Job, those with the highest productivity relative to their wage arguably are the most 11 kely to find a better job elsewhere and thus would be the most likely to leave this firm. Nonetheless, as a logical possibility, the retiring workers might be pald much more than their marginal revenue product and this might have been the motivation for the window, but if so the plan was 111-designed and the older employees were unproductive indeed.

Thus, based on these data it is unlikely in our judgment that the goal of the window plan was to induce older workers to retire because their productivity was low relative to their salaries. The evidence is more consistent with a desire to reduce the overall size of the labor force, or to 
reduce the number of older employees to allow promotion of younger employees. The window plan is a conventent and powerful means of reducing employment without having to resort to layoffs. 


\section{References}

Bulow, J. 1981. "Early Retirement Pension Benefits." NBER Working Paper No. 654 .

Burkhauser, Richard V. 1979. "The Pension Acceptance Decision of Older Workers," in Journal of Human Resources XIV(1), PP. 63-75.

Fields, Gary S. and Olivia Mitchell. 1982. "The Effects of Pensions and Earnings on Retirement: A Review Essay," in R. Ehrenberg (ed.), Research in Labor Economics, Vol, 5, pp. 115-156. Greenwich, CT: JAL Press.

Fields, Gary S. and Ollvia Mitchell. 1984, Retirement, Pensions and Social Security. Cambridge, MA: MIT Press.

Hogarth, Jeanne M. 1988. "Accepting an Early Retirement Bonus: An Empirical Study," in Journal of Human Resources XXIII(1), PP. 21-33.

Kotlikoff, Laurence J. and David A. Wise. 1985. "Labor Compensation and the Structure of Private Pension Plans: Evidence for Contractual versus Spot Labor Markets," in D. Wise (ed.), Pensions, Labor, and Individual Choice, Pp. 55-87. Chicago: University of Chicago Press.

Kotlikoff, Laurence J. and David A. Wise. 1987. "The Incentive Effects of Private Pension Plans," in Z. Bodie, J. Shoven, and D. Wise (eds.), Issues in Pension Economics, Pp. 283-339. Chicago: University of Chicago Press.

Kotlikoff, Laurence J. and David A. Wise. 1989. "Employee Retirement and a Firm's Pension Plan," in D. Wise (ed.), The Economics of Aging. Chicago: University of Chicago Press. Pp. 279-330.

Lazear, Edward P. 1979. "Why Is there Mandatory Retirement?" in Joumal of Political Economy 87:1261-64. 
Lazear, Edward P. 1983. "Pensions as Severance Pay," In Z. Bodie and J. Shoven (ed.), Financial Aspects of the United States Pension System. Chicago: University of Chicago Press.

Lunsdaine, Robin L., James H. Stock, and David A. Wise. 1989. "Windows and Retirement." Forthcoming in Annales d'Economie et de Statistique. Stock, James H. and David A. Wise. 1988a. "The Pension Inducement to Retire: An Option Value Analysis." NBER Working Paper No. 2660, forthcoming in D. Wise (ed.), Issues in the Economics of Aging. Chicago: University of Chicago Press.

Stock, James H. and David A. Wise. 1988b. "Pensions, The Option Value of Work, and Retirement." NBER Working Paper No. 2686, forthcoming in Econometrica. 
Table 1. Firm window plan: approximate bonus months by age and years of service.

\begin{tabular}{|c|c|c|c|c|c|c|c|c|c|c|c|c|c|c|c|}
\hline \multirow{2}{*}{$\begin{array}{l}\text { Years } \\
\text { of } \\
\text { Service }\end{array}$} & \multicolumn{15}{|c|}{ Age } \\
\hline & 55 & 56 & 57 & 58 & 59 & 60 & 61 & 62 & 63 & 64 & 65 & 66 & 67 & 68 & 69 \\
\hline 10.19 & 0.0 & 1.7 & 4.2 & 6.7 & 9.0 & 10.9 & 12.3 & 13.1 & 13.2 & 12.5 & 11.1 & .9 .0 & 6.3 & 3.1 & 0.0 \\
\hline $20-29$ & 0.0 & 3.4 & 6.4 & 8.8 & 10.6 & 11.9 & 12.5 & 12.5 & 12.0 & 10.9 & 9.4 & 7.3 & 4.9 & 2.3 & 0.0 \\
\hline $30-39$ & 0.1 & 6.3 & 9.2 & 11.0 & 11.9 & 12.3 & 12.1 & 11.4 & 10.4 & 9.1 & 7.5 & 5.7 & 3.7 & 1.7 & 0.0 \\
\hline 40.49 & 1.5 & 11.0 & 12.5 & 12.8 & 12.5 & 11.8 & 10.9 & 9.7 & 8.4 & 7.0 & 5.6 & 4.1 & 2.6 & 1.1 & 0.0 \\
\hline
\end{tabular}


Table 2. Bonus schedule for the firm plan versus optimal plans.

\begin{tabular}{|c|c|c|c|c|c|c|c|c|c|c|c|c|c|c|c|}
\hline \multirow{2}{*}{$\begin{array}{l}\text { Years } \\
\text { of } \\
\text { Service }\end{array}$} & \multicolumn{15}{|c|}{ Age } \\
\hline & 55 & 56 & 57 & 58 & 59 & 60 & 61 & 62 & 63 & 64 & 65 & 66 & 67 & 68 & 69 \\
\hline
\end{tabular}

\section{Beta Approximation to Firm Plan}

\begin{tabular}{|c|c|c|c|c|c|c|c|c|c|c|c|c|c|c|c|}
\hline $0-19$ & 0.0 & 1.7 & 4.2 & 6.7 & 9.0 & 10.9 & 12.3 & 13.1 & 13.2 & 12.5 & 11,1 & 9.0 & 6.3 & 3.1 & 0.0 \\
\hline & 00 & 3.4 & 6.4 & 8.8 & 10.6 & & 12.5 & 12.5 & & 10.9 & 9.4 & 7.3 & 4.9 & & 0 \\
\hline & 0.1 & 63 & 9.2 & 11.0 & 11.9 & 12.3 & & & & & & & 3.7 & & \\
\hline & 1.5 & 11.0 & 12.5 & 12.8 & 12.5 & 11.8 & 10.9 & 9.7 & 8. 4 & 7.0 & 5.6 & 4.1 & 2.6 & 1.1 & 0 \\
\hline
\end{tabular}

\section{Optimal Cost-Minimizing Plan}

\begin{tabular}{|c|c|c|c|c|c|c|c|c|c|c|c|c|c|c|c|}
\hline 10.19 & 16.0 & 13.8 & 11.3 & 9.1 & 7.2 & 5.5 & 4.1 & 3.0 & 2.0 & 1.3 & 0.7 & 0.4 & 0.1 & 0.0 & 0.0 \\
\hline $20-2$ & 16.1 & 13.8 & 11.3 & 9.1 & 7.2 & 5.5 & 4.1 & & 2.0 & & 0.7 & 0.4 & 0.1 & 0.0 & 0.0 \\
\hline 0 & 16.2 & 13.8 & 11.3 & & & & & & & & 0.7 & 0.4 & & 0.0 & 0.0 \\
\hline 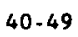 & 16.3 & 13.8 & 11.3 & 9.1 & 7.2 & 5.5 & 4.1 & 3.0 & 2.0 & 1.3 & 0.7 & 0.4 & 0.1 & 0.0 & 0.0 \\
\hline
\end{tabular}

Optimal Current-Retirement-Maximlzing Plan

\begin{tabular}{|c|c|c|c|c|c|c|c|c|c|c|c|c|c|c|c|}
\hline $0-19$ & 15.7 & 14.1 & 13.0 & 11.9 & 10.9 & 9.8 & 8.7 & 7.7 & 6.6 & 5.5 & 4.4 & 3.4 & 2.3 & 1.2 & 0.0 \\
\hline & 16.8 & 14.3 & 13.1 & 11.9 & 10.8 & 9.8 & 8.7 & 7.6 & 6.5 & 5.5 & 4.4 & 3.3 & 2.2 & 1.1 & 0.0 \\
\hline & 18.0 & 14.4 & 13.1 & 11.9 & 10.8 & 9.7 & 0.0 & 1.0 & 6.5 & $\cdots$ & 4.4 & 3.3 & 2.2 & 1.1 & 0 \\
\hline-4 & 19.3 & 14.6 & 13.2 & 11.9 & 10.8 & 9.7 & 8. 6 & 7.5 & 6.4 & 5.4 & 4.3 & 3.2 & 2.2 & 1.1 & 0.0 \\
\hline
\end{tabular}

Optimal Future-labor-Years-Minimizing Plan

\begin{tabular}{|c|c|c|c|c|c|c|c|c|c|c|c|c|c|c|c|}
\hline $10-19$ & 19.3 & 13.4 & 12.2 & 11.2 & 10.3 & 9.4 & 8.5 & 7.6 & 6.7 & 5.7 & 4.8 & 3.8 & 2.8 & 1.6 & 0.0 \\
\hline & 2.1 & 13.7 & 12.3 & 11.2 & 10.2 & 9.3 & 8.4 & 7.5 & & 5.6 & 4.7 & 3.7 & & 1.6 & 0.0 \\
\hline & 25.4 & 14.0 & 12.4 & 11.2 & 10.2 & 9.2 & 8.3 & 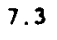 & 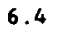 & 5.5 & 4.6 & 3.6 & 2.6 & 1.5 & 0.0 \\
\hline 10 & 29.2 & 14.3 & 12.5 & 11.2 & 10.1 & 9.1 & 8.2 & 7.2 & 6.3 & 5.4 & 4.5 & 3.6 & 2.6 & 1.5 & 0.0 \\
\hline
\end{tabular}


Table 3, Comparison of Optimal with Other Window Plans

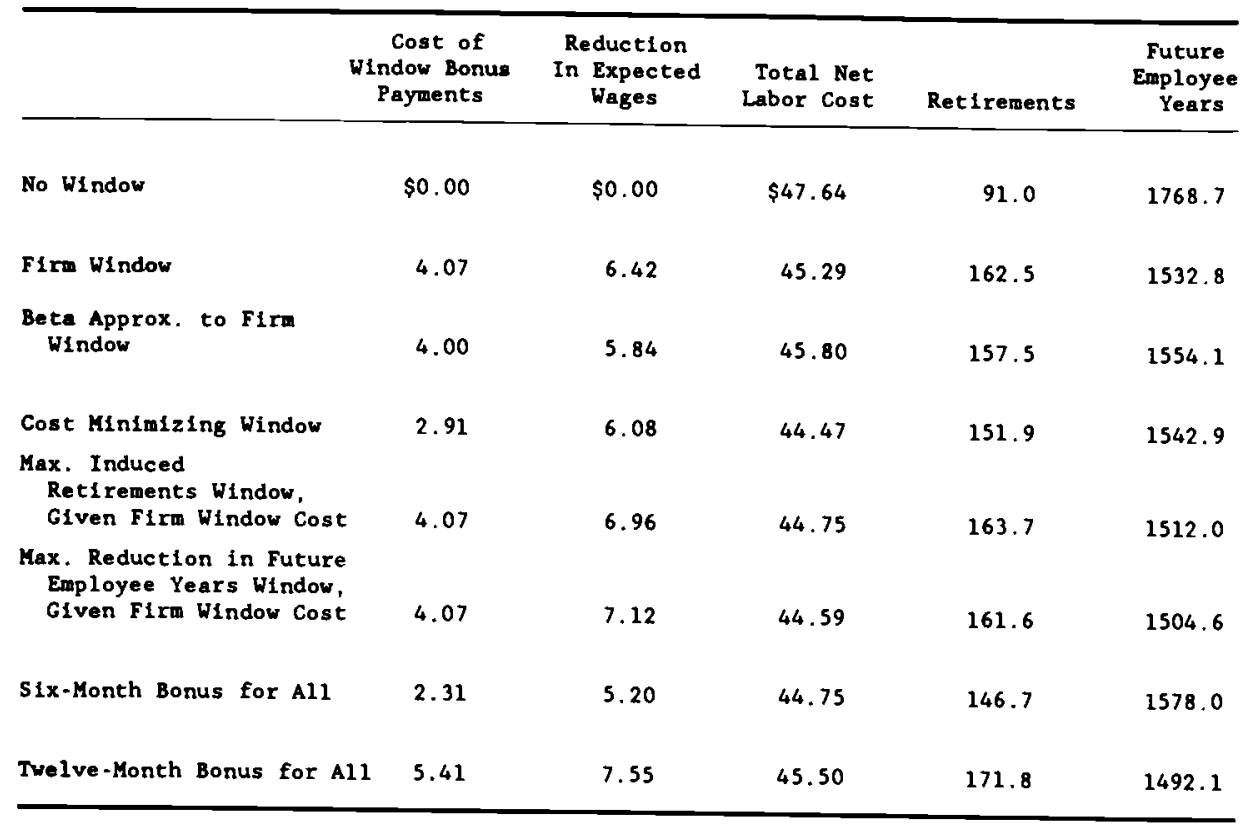

Note: All values are calculated for the persons in our sample who were 55 and older and who were in the firm on January 1, 1982. Dollar amounts are in millions. 


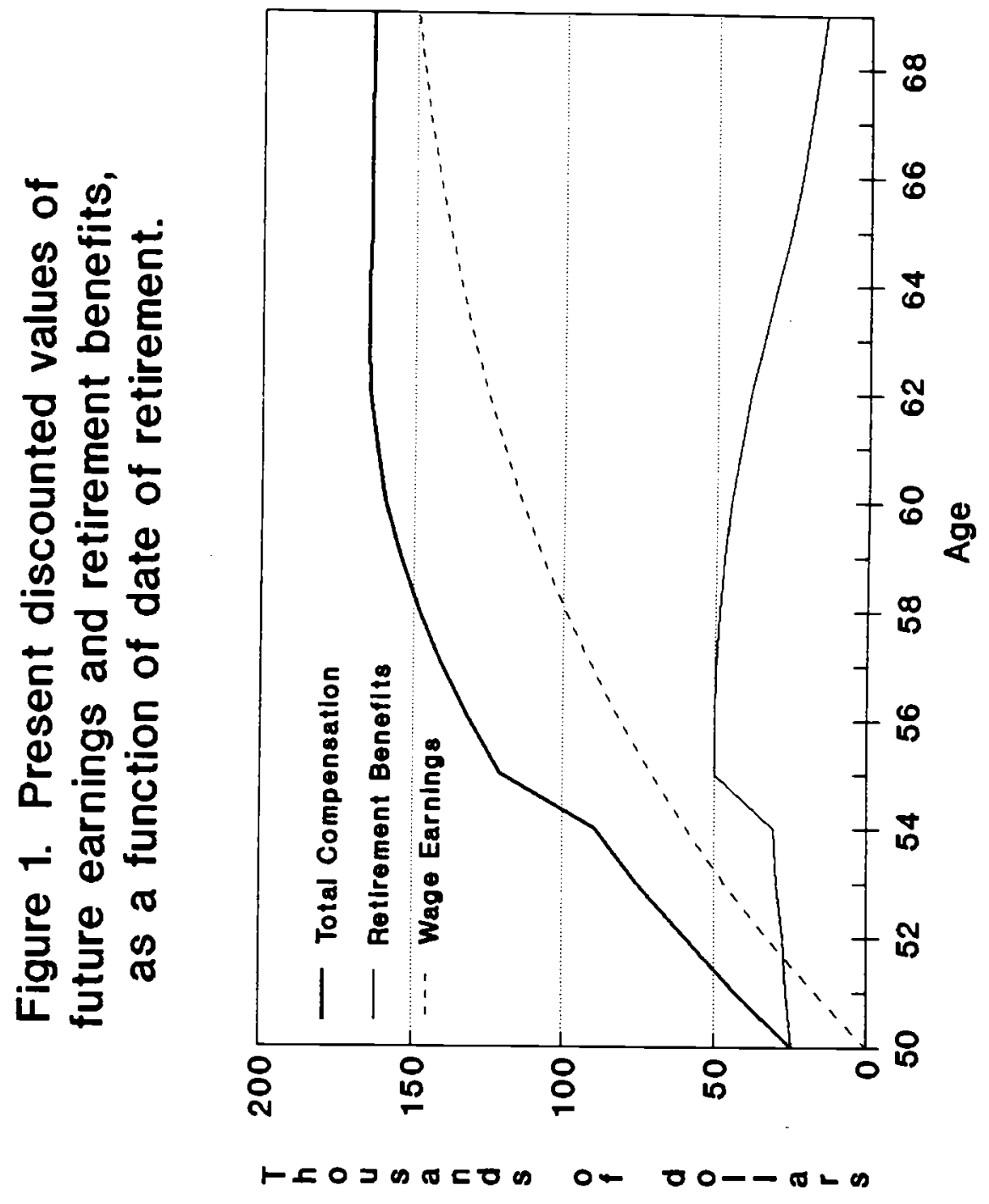




\section{Figure 2. Actual versus predicted retirement rates, 1980.}
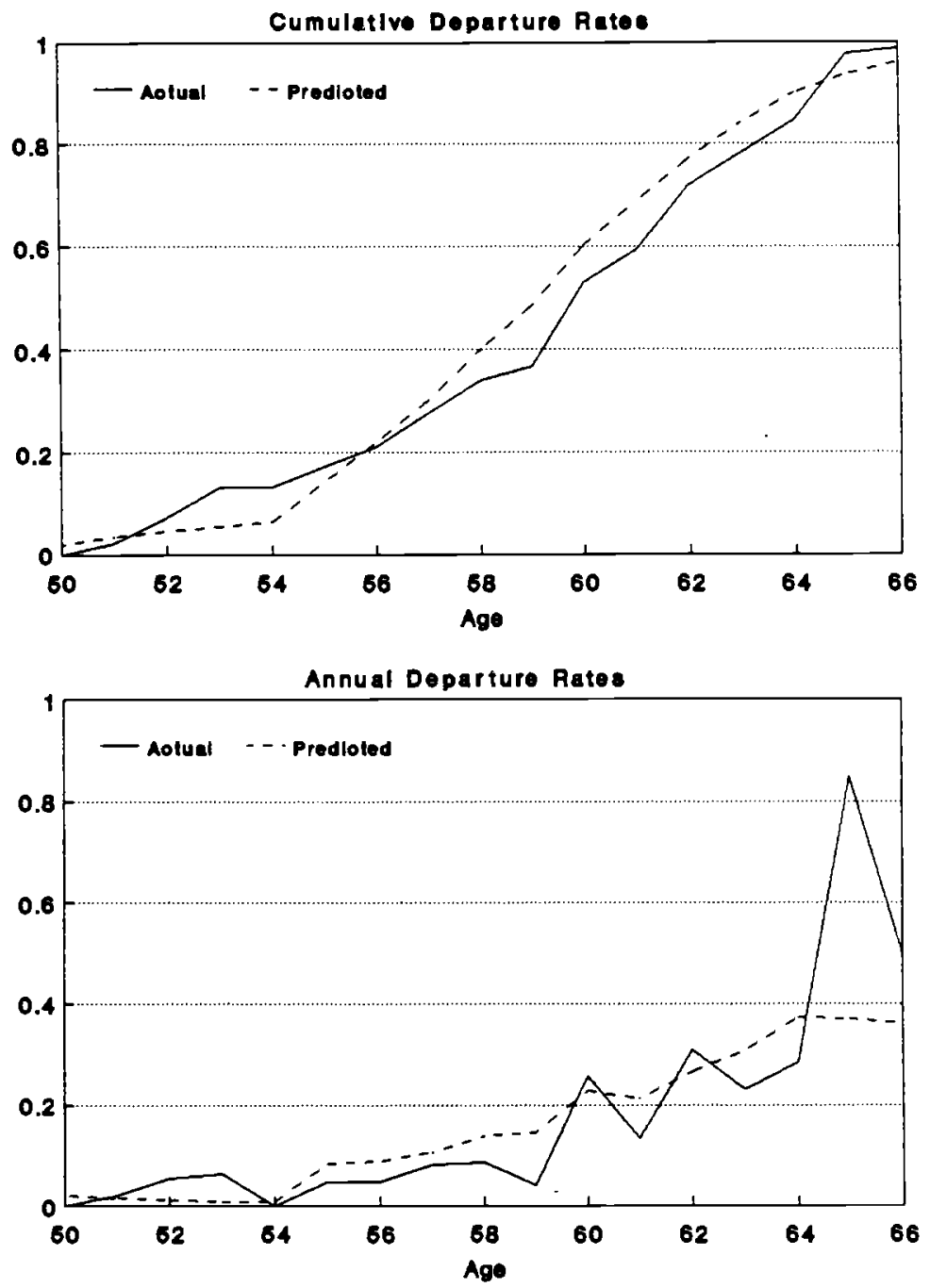

Nole: The bottom panel thowe deparlure (hazard) ratee by age. The top panel shows the implled proportion of workere employed at ace 50 who would have lelt ihe firm by ubeequent ages, baed on the departure rates by eqe ehown in the botlom panel. 
Figure 3. Simulated effect in 1982 of 1982 window plan instead of usual plan provisions, based on 1980 parameter estimates.
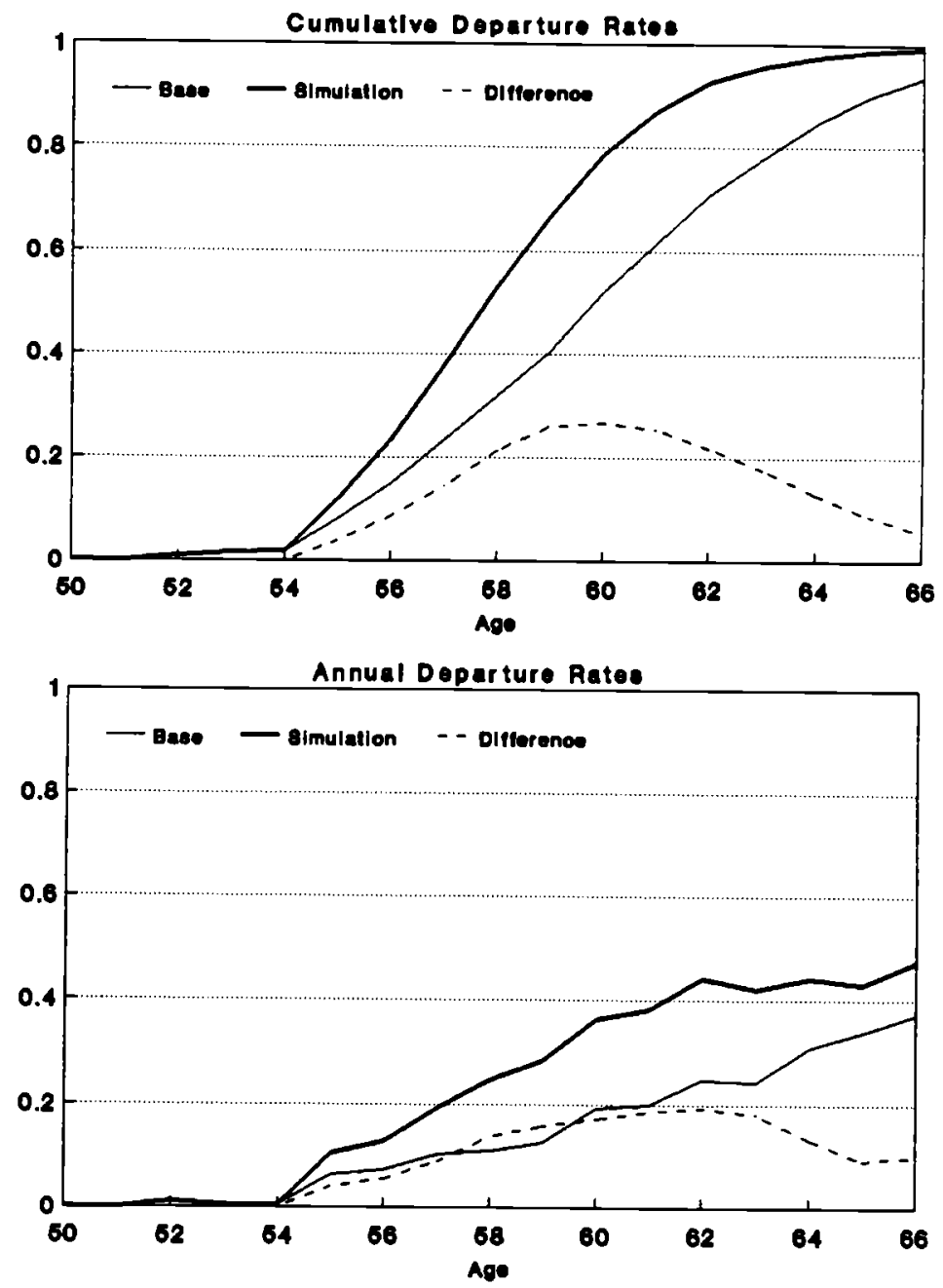

Note: The bottom panel ohowe deperture (hazard) pates by age. The top panol onowe the implled proportlon of workere employed at age 50 who would have lell the lirm by

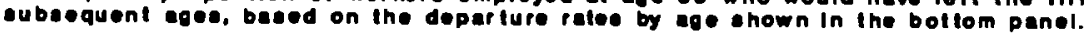


Figure 4. Actual retirement rates in 1981 and 1982 vs. simulated 1982 retirement rates under the window plan, based on 1980 parameter estimates.
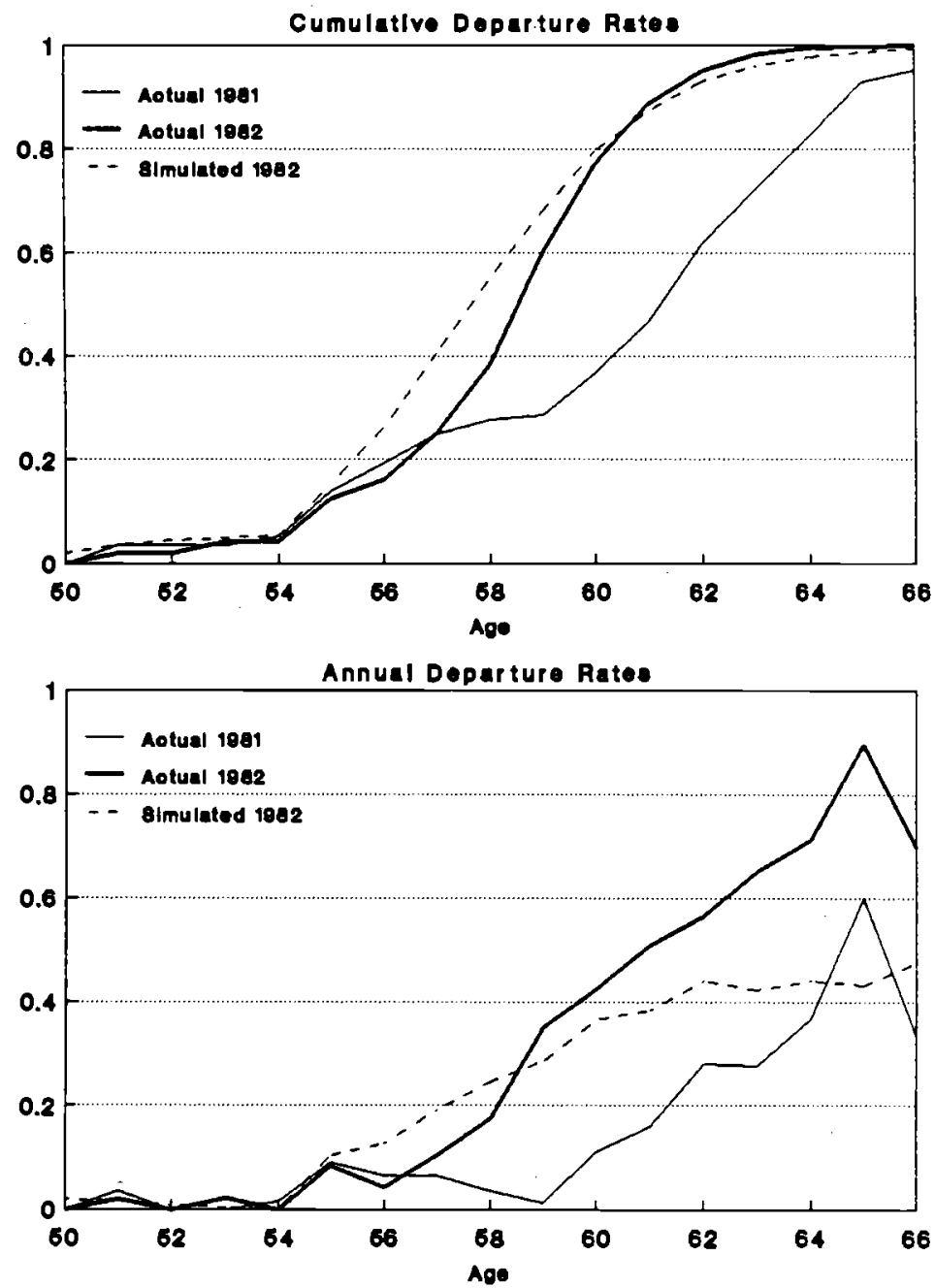

Note: The bottom panel showe departure (hazard) rates by age. The top panel ohowa the Implled proportion of worker employed at age 50 who would have left the flrm by eubeequent agee, based on the departure ratee by age ehown in the bottom panel. 
Figure 5. Simulated retirement rates under a window plan with a 6-month and a 12-month bonus for all employees 55 and over.
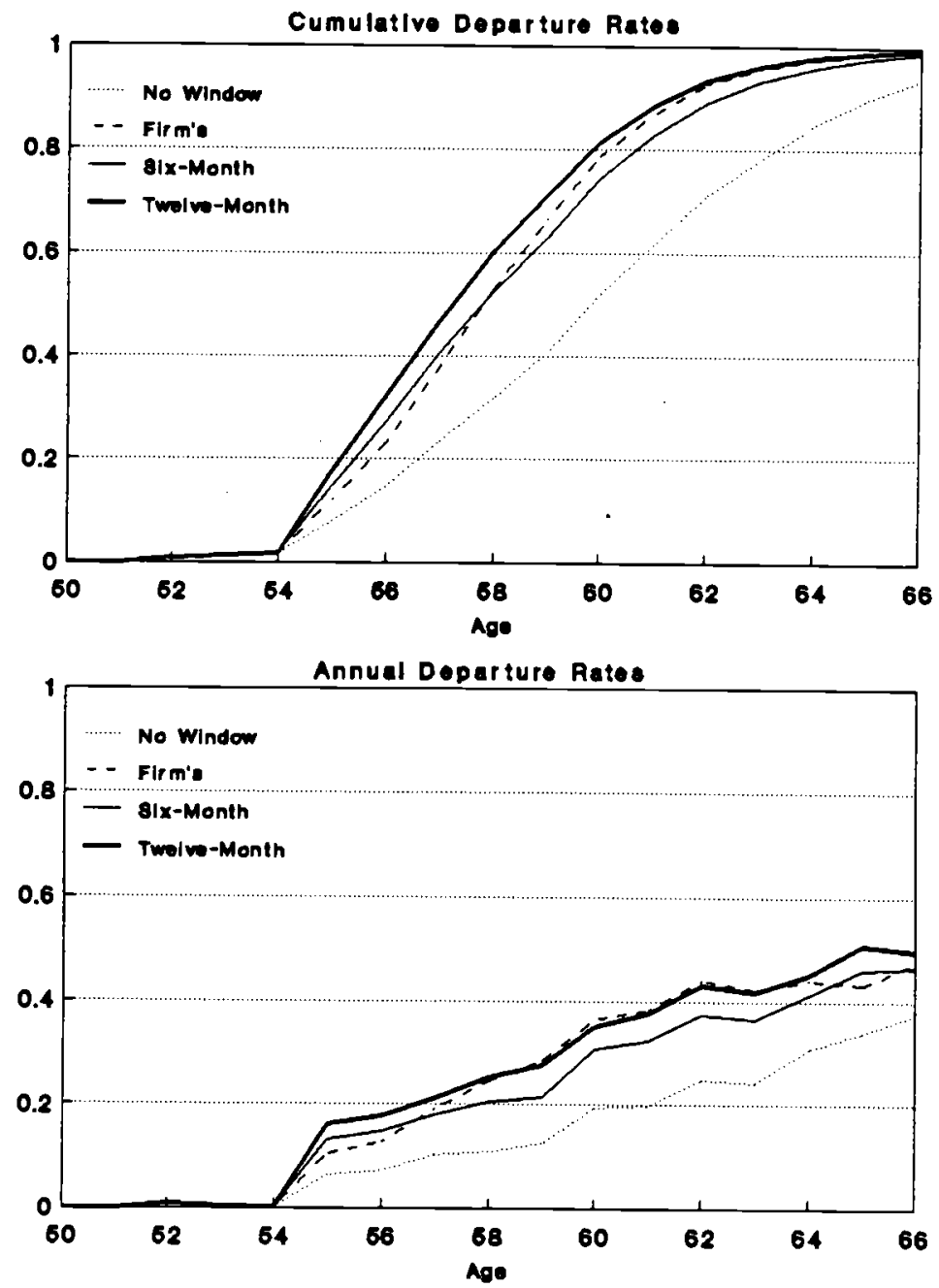

Nole: The bottom panel showe departure (hazard) ratee by age. The top panel ohowe the Implled proportion of workere employed at age 00 who would have lett the ilfm by eubeequent egee, baed on the departure ratee by age ehown in the boltom panet. 
Figure 6. Annual simulated 1982 retirement rates under the firm plan versus retirement rates under the beta approximation to the firm plan.
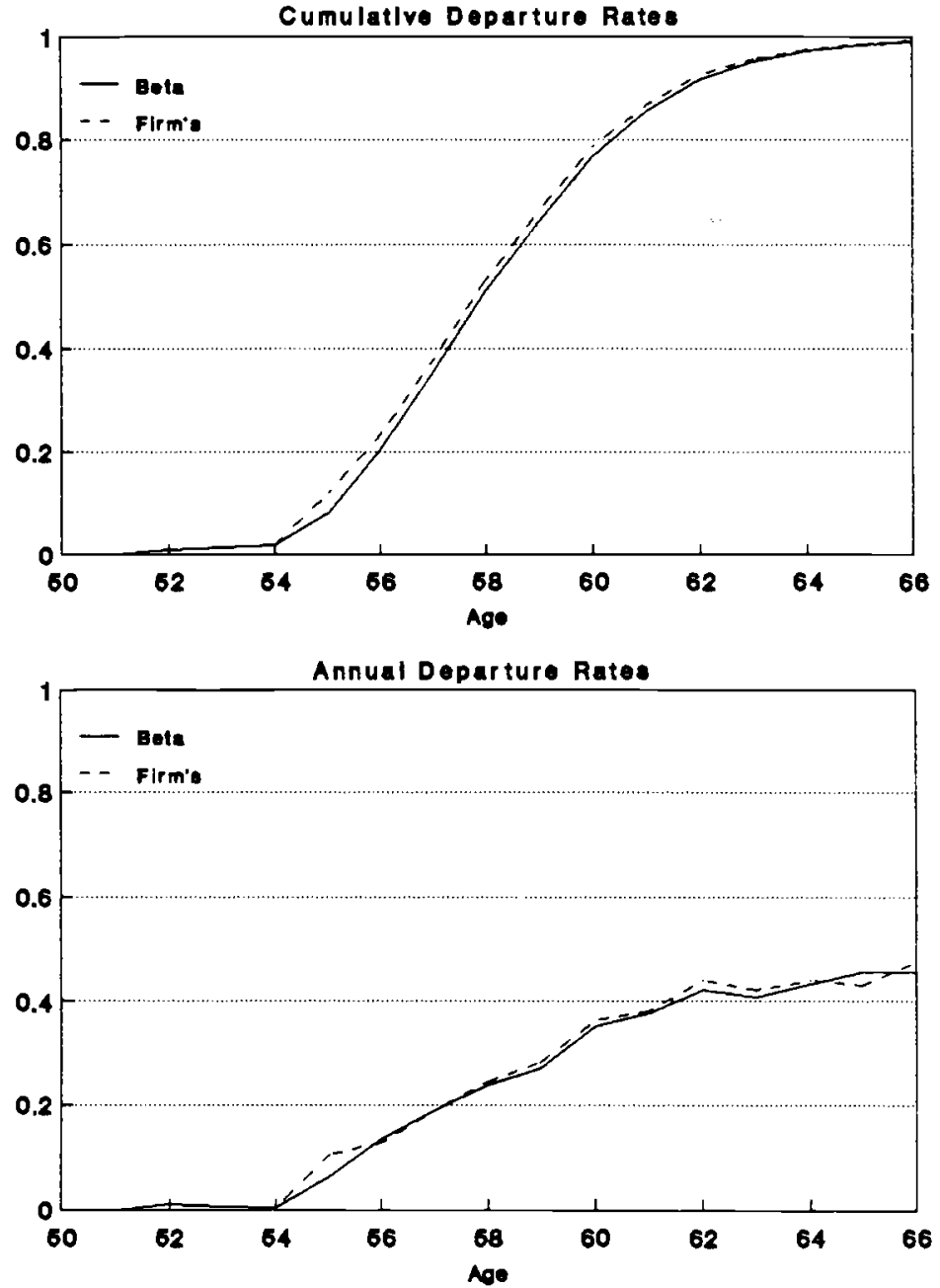

Note: The botlom penel shows departure (hazerd) rates by age. Tho top panel ehowe the implled proportion of workere employed at age 60 who would have left ine ilrm by subeequenty ages, based on the departure rates by age shown in the bottom penel. 
Figure 7. Departure rates induced by the optimal cost-minimizing plan versus the firm's plan.
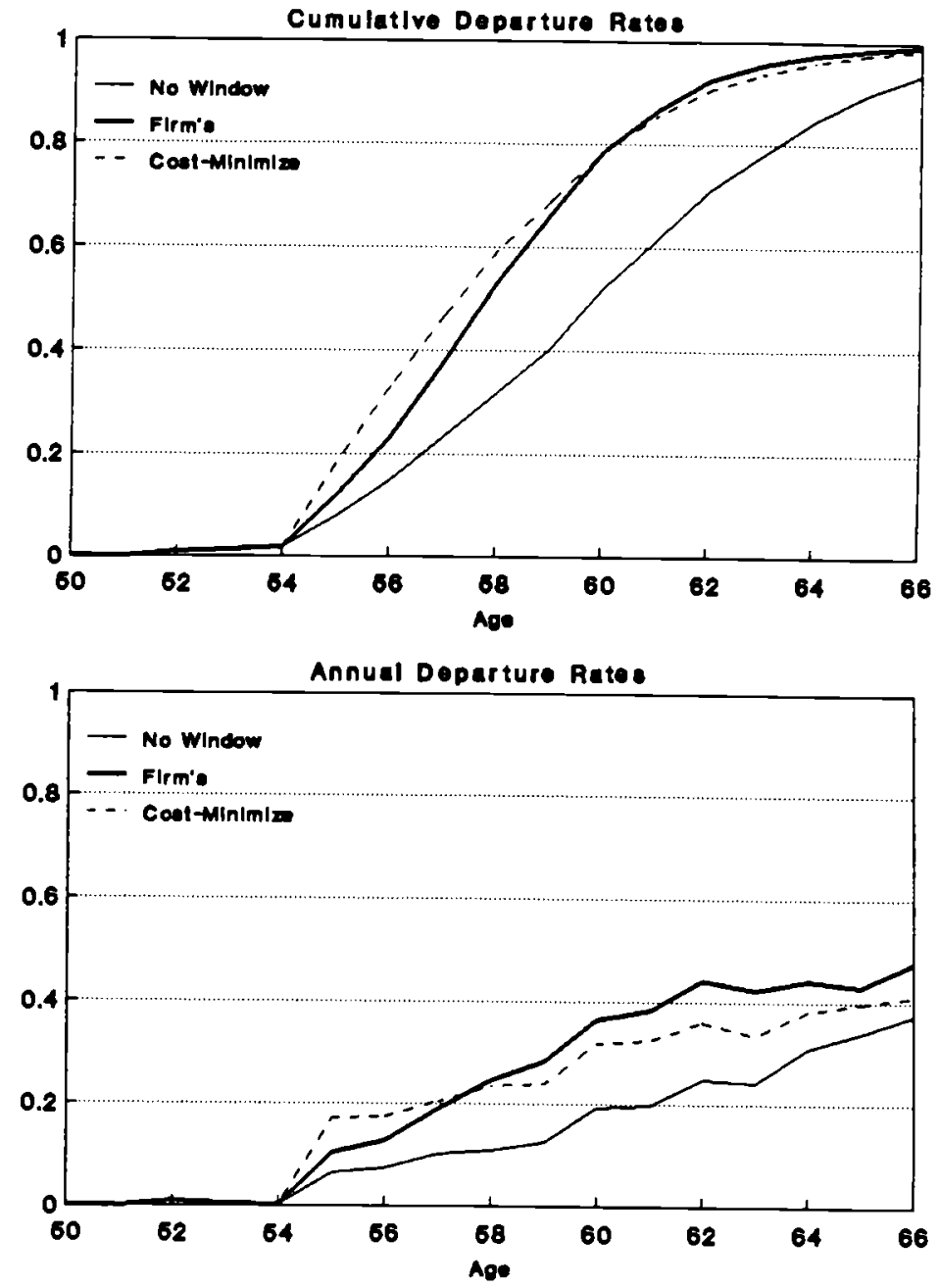

Note: The bottom panel ohowe departure (haxard) rates by age. The top panel ahowe the Implled proportlon of workere employed at age 50 who would have lefl the flrm by oubeequent agee, beed on the departure rates by ege ohown in the botiom panel. 
Figure 8. Departure rates induced by the optimal current-retirement-maximizing plan versus the firm's plan.
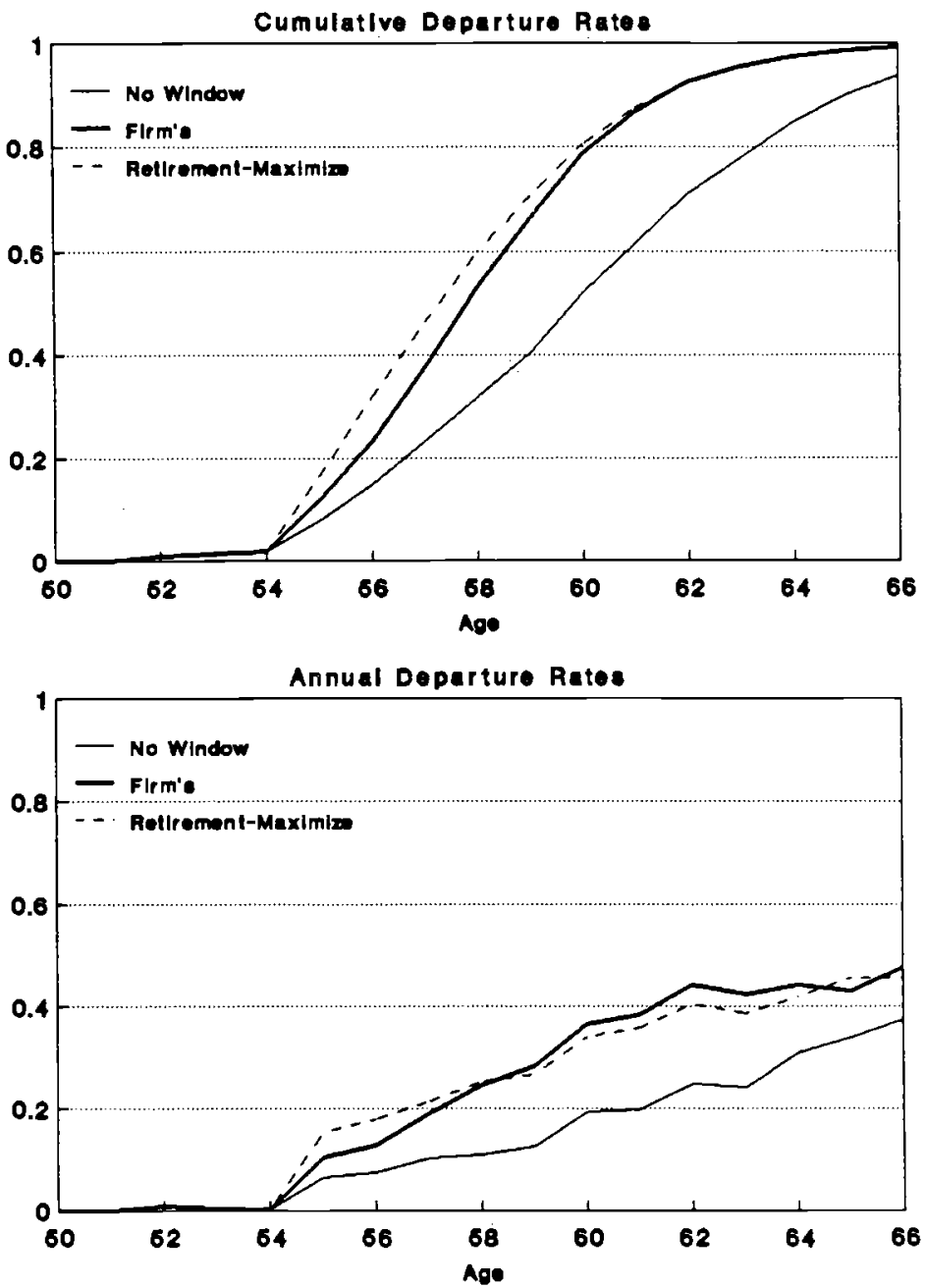

Note: The bottom panel showe departure (hazard) rated by age. The lop panel ahows the implled proportlon of workere employed at age 60 who would heve left ine flrm by oubequent egea, based on the departure rates by age ehown in the botiom panel. 
Figure 9. Departure rates induced by the optimal future-labor-years-minimizing plan versus the firm's plan.
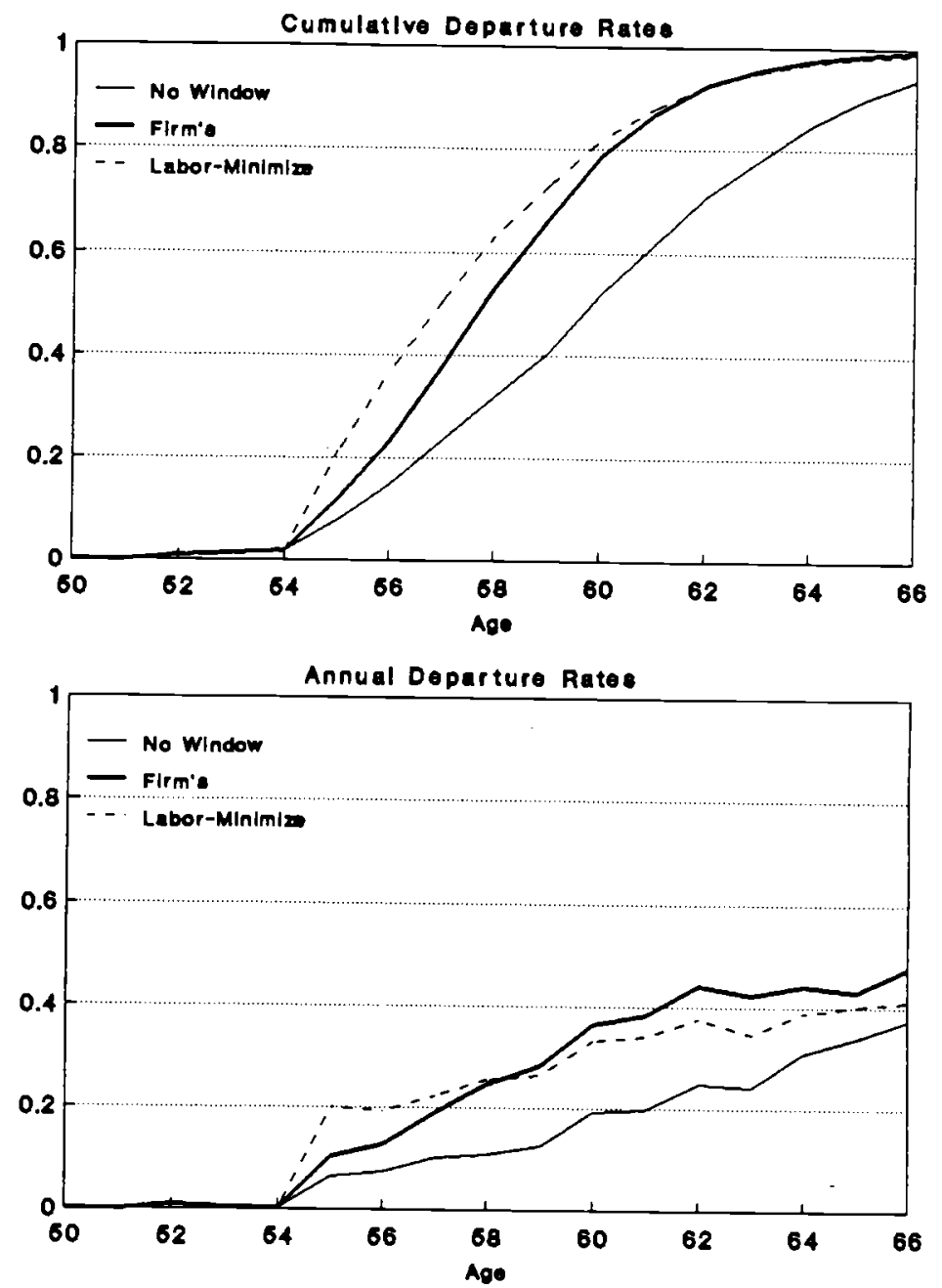

Nole: The botlom panel howe departure (hazard) ratee by age. The top panel showe the Implled proportion of workere employed at age 50 who would have lell the lirm by ubsequent ages. baed on the deperture rates by age ehown in the botlom panel. 